\title{
Hardness and Wear Resistance of Adamite for Work Rolls in Hot Rolling Mill*
}

\author{
By Hiroshi NOGUCHI, ** Hisashi HIRAOKA, ** Yasuo WATANABE** \\ and Yasuhiro SAYAMA**
}

\begin{abstract}
Synopsis
The hardness of adamite roll materials for hot work rolls depends on their microstructures; the amount and hardness of coarse carbides and the hardness of matrix. The high-hardened adamite roll materials are excellent in wear resistance when the amount of coarse carbides is about $8 \%$, but the wear resistance deteriorates when the amount of coarse carbides exceeds a critical level.

The reason is considered to be as follows: As the volume of coarse carbides increases, the spacing between coarse carbides decreases and the area of coarse carbides in contact with hot strip surfaces also increases, to induce a partial disintegration of brittle coarse carbides.

The high-hardened adamite rolls with about $8 \%$ of coarse carbides have a hardness from $H s 65$ to 70 and can be used for hot work rolls with satisfactory results.
\end{abstract}

Key words: wear; hardness; roll material for hot rolling; microscopy; quantitative analysis of microstructure; adamite.

\section{Introduction}

It is known that the adamite roll materials used for work rolls in hot rolling mills are higher in toughness than the cast iron roll materials, but are lower in wear resistance because of the low hardness from $\mathrm{Hs} 40$ to 60 .

Recently, as the hot rolling condition becomes severer, the rolls are required to have a higher wear resistance. If the adamite rolls can be hardened to improve their wear resistance, it is expected that the use of high-hardened adamite rolls for hot work rolls will increase.

The adamite roll materials can be considered as composite materials of two phases of coarse carbides and matrix. As a consequence the hardness of these roll materials may be markedly affected by the amount and hardness of coarse carbides. However, the wear resistance of roll materials deteriorates, if the amount of coarse carbides is increased above a critical value. ${ }^{1,2)}$ Therefore, the microstructures of these roll materials should consist of the coarse carbides of an optimum amount and distribution to prepare a good combination of high hardness and wear resistance.

The present report presents the following:

1) The experimental results concerning the relation between hardness and microstructure of the roll materials; the amount of coarse carbides and the hardnesses of both coarse carbides and matrix.

2) Optimum microstructures of the hardened adamite roll materials for improvement of the wear resistance.
3) The technological approach to obtain the optimum structure.

\section{Experimental Procedures}

\section{Materials}

Eleven charges of the adamite roll materials with a different $\mathrm{C}, \mathrm{Cr}, \mathrm{Ni}$ and $\mathrm{Mn}$ content were melted by using a $20 \mathrm{~kg}$ high-frequency electric induction furnace. The chemical composition of each charge is shown in Table 1.

Charge Nos. 1 to 5 were different in the $\mathrm{G}$ contents from 1.34 to $2.59 \%$ for revealing the effects of $\mathrm{C}$ contents. Charge No. 3 and Nos. 6 to 9 had the various Cr contents from 0.98 to $2.91 \%$ to see the effects of Cr contents. Charge Nos. 2 and 10 were used clarify the effects of Mn contents and Charge Nos. 3 and 11 to clarify the effects of $\mathrm{Ni}$ contents.

Test blocks of 60-mm diameter and 150-mm length were made by casting these materials in sand molds and annealed at $1000^{\circ} \mathrm{C}$ for $5 \mathrm{~h}$ followed by furnace cooling for reducing the segregation and for homogenizing of the cast structure. These blocks were then normalized at $950^{\circ} \mathrm{C}$ for $5 \mathrm{~h}$ and tempered at $550^{\circ} \mathrm{C}$ for $5 \mathrm{~h}$. Discs of $50-\mathrm{mm}$ diameter and $10-\mathrm{mm}$ thickness for wear testing were machined from the test blocks after the heat treatments.

\section{High Temperature Wear Testing}

High temperature wear testing of the roll materials was carried out by using a twin-disc-type high temperature wear testing machine which can simulate

Table 1. Chemical compositions of the adamite roll materials. (wt $\%)$

\begin{tabular}{rrrrrrrr}
\hline & $\mathrm{G}$ & $\mathrm{Si}$ & $\mathrm{Mn}$ & $\mathrm{Ni}$ & $\mathrm{Gr}$ & $\mathrm{Mo}$ \\
\hline 1 & 1.34 & 0.56 & 0.54 & 1.00 & 1.49 & 0.65 \\
2 & 1.68 & 0.59 & 0.54 & 1.01 & 1.48 & 0.61 \\
3 & 1.91 & 0.58 & 0.54 & 1.00 & 1.48 & 0.59 \\
4 & 2.21 & 0.57 & 0.56 & 1.00 & 1.50 & 0.60 \\
5 & 2.59 & 0.56 & 0.55 & 1.00 & 1.46 & 0.61 \\
6 & 1.95 & 0.64 & 0.58 & 1.00 & 0.98 & 0.64 \\
7 & 2.06 & 0.57 & 0.54 & 1.00 & 1.94 & 0.61 \\
8 & 1.98 & 0.58 & 0.56 & 1.00 & 2.41 & 0.61 \\
9 & 1.98 & 0.58 & 0.58 & 1.00 & 2.91 & 0.62 \\
10 & 1.72 & 0.55 & 1.23 & 1.00 & 1.47 & 0.61 \\
11 & 1.98 & 0.58 & 0.58 & 0.52 & 1.47 & 0.60 \\
\hline
\end{tabular}

* Based on the paper presented to the 113th ISIJ Meeting, April 1987, S584, at The University of Tokyo in Tokyo. Manuscript received on August 28, 1987; accepted in the final form on February 12, 1988. (C) 1988 ISIJ

** Iron \& Steel Research Laboratories, Technical Research Division, Kawasaki Steel Corporation, Kawasaki-cho, Handa 475. 
the hot wear behavior of the actual roll materials. Figure 1 shows the main parts of the test machine, and its mechanism is schematically shown in Fig. 2. The machine consists of two discs; the upper disc named a heat disc simulates the rolled materials and the lower disc named a test disc simulates the work roll. Both heat and test disc are designed to rotate in the opposite direction.

The heat disc has a size of 190-mm diameter and $15-\mathrm{mm}$ thickness and is made of S45C steel. The standard size of test disc is $50-\mathrm{mm}$ diameter and 10$\mathrm{mm}$ thickness, although its diameter can be varied from 50 to $80 \mathrm{~mm}$. The heat disc can be heated up to $1100^{\circ} \mathrm{C}$ during the test in a high-frequency induction heating apparatus.

A load simulating the rolling force can be applied up to $500 \mathrm{kgf}$ with an oil hydraulic system. The test disc can be rotated at a rate from 700 to $6000 \mathrm{rpm}$ by a motor. The heat disc is rotated at a slower rate than the test disc through a reduction gear.

The slipping rates between heat disc and test disc can be set in a range from 3.9 to $35.1 \%$ by selecting the gear ratio and the diameter of test discs. The temperature of test disc is controlled by a flow rate of cooling water. The temperature of heat and test discs are measured with an individual two-colorpyrometer.

The temperature, rolling torque and load are measured during wear test. The specific wear loss is defined and measured by a wear loss per unit sliding distance on test discs.

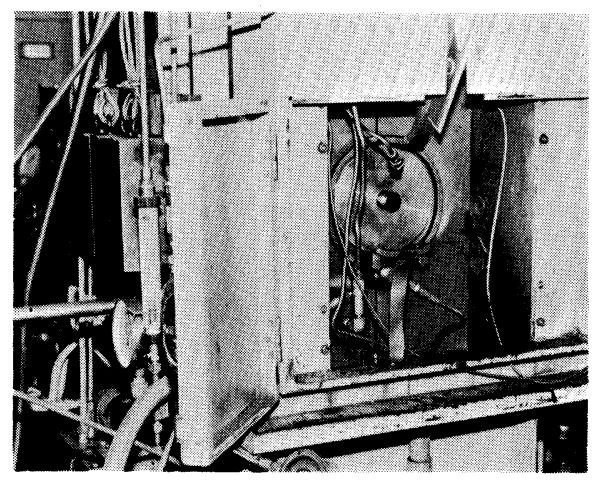

Fig. 1. The main parts of high temperature wear testing machine.

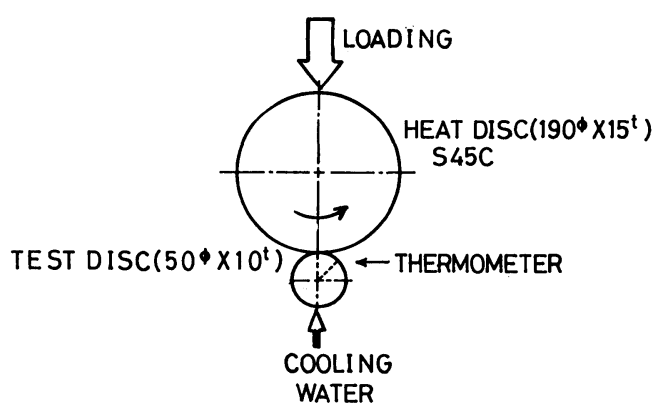

Fig. 2. A schematic drawing of mechanism of wear testing machine.

\section{Quantitative Analysis of Microstructure}

Coarse carbide is defined as the term of the proeutectoid cementite and the eutectic cementite. The interspacing and the volume fraction of coarse carbides in the roll materials were measured with an image analyzer.

The microstructures etched with a nital etchant were inputted as digital image. The size of an image frame was $512 \times 512$ pix. The magnification was $\times 100$ and the resolution was $3 \mu \mathrm{m} / \mathrm{pix}$. The coarse carbide images were discriminated from an enlarged microstructure image. Area percent of the coarse carbide was measured as carbide volume fraction. The interspacing of coarse carbide was defined as the mean free path among coarse carbides as shown in Fig. 3, which was measured with the scanning of 128 lines frame in two perpendicular directions. The interspacing between coarse carbide and image frame was omitted to measure the mean free path of coarse carbide. The carbide volume fraction and the distance between carbide were calculated from twenty image frames in each roll material.

\section{Results and Discussion}

1. Effects of Chemical Composition on the Structure and Hardness

1. Effects of Chemical Composition on the Amount of Coarse Carbides

There is no remarkable change in the matrix structure among the adamite roll materials, although the size of coarse carbides varies with chemical composition. Figure 4 shows the effect of $\mathrm{G}$ and $\mathrm{Cr}$ contents on the morphology of coarse carbide in adamite roll materials. The morphology of coarse carbides is found to be markedly affected by $\mathrm{G}$ content: the coarse carbide becomes larger in size and distributes in a network form with increasing $\mathrm{C}$ content. Eutectic carbides can be seen in the adamite roll materials containing more than $1.9 \% \mathrm{C}$ content.

However, the size of coarse carbides seems to be less affected by the $\mathrm{Cr}$ content within the limit of the present experiment. These experimental results are considered to be caused by the presence of $\mathrm{Cr}$ which lowers the temperature of precipitation of both grainboundary-cementite and intergranular plate-like cementite and also retards their coarsening. ${ }^{3)}$

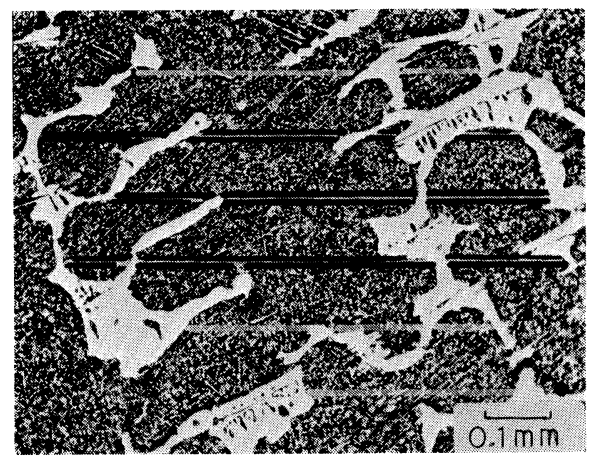

Fig. 3. Measuring method of carbide spacing. 


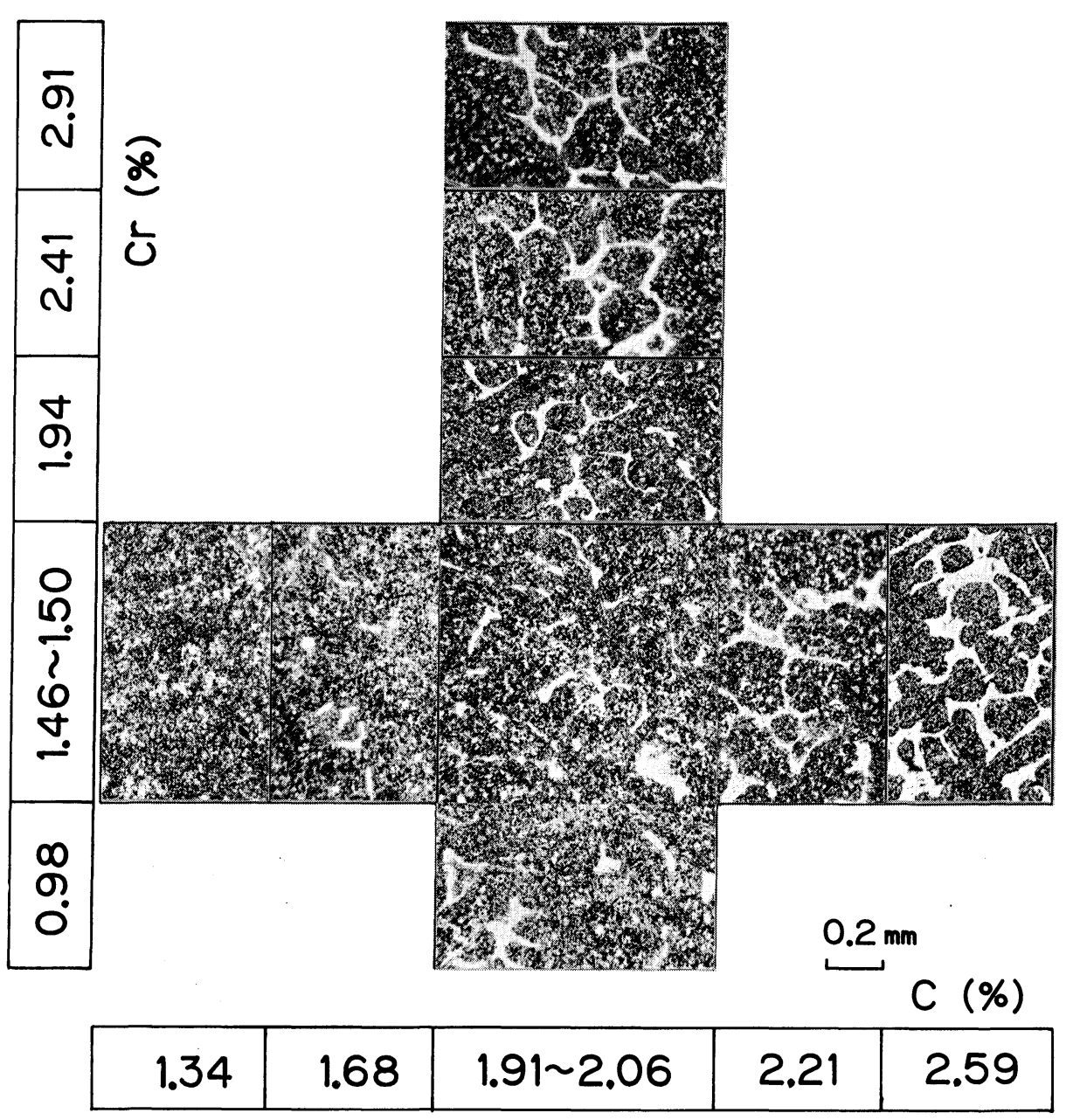

Fig. 4.

Effect of $\mathrm{C}$ and $\mathrm{Cr}$ contents on the morphology of coarse carbides in adamite.
Figure 5 shows the dependence of the coarse carbide volume fraction on the $\mathrm{C}$ and $\mathrm{Cr}$ contents. Along with an increase of $\mathrm{C}$ contents, the amount of coarse carbides increases markedly. However, the amount of coarse carbides seems to increase at a lower rate with increasing $\mathrm{Cr}$ content.

If these data for varying $\mathrm{Cr}$ contents are rearranged according to $\mathrm{C}$ content, the plots shift in the direction of the respective arrows. Therefore, this experimental result suggests that the amount of coarse carbide is affected remarkably by $\mathrm{C}$ content and slightly by $\mathrm{Cr}$ content.

Also, it is found that $\mathrm{Mn}$ and $\mathrm{Ni}$ contents affect scarcely the amount of coarse carbide.

\section{Effects of Chemical Composition on the Hardness of} Coarse Carbides

Figure 6 shows the relation between the hardness of coarse carbides and the $\mathrm{G}$ and $\mathrm{Cr}$ contents.

(1) The hardness of coarse carbides decreases gradually with increasing $\mathrm{C}$ content at a fixed $\mathrm{Cr}$ content.

(2) The hardness of coarse carbides increases significantly with increasing $\mathrm{Cr}$ content in a range of $\mathrm{C}$ content from 1.91 to $2.06 \%$.

These experimental results seem to be a result of solid solution hardening due to the presense of $\mathrm{Cr}$ in coarse carbides.

The hardness of coarse carbides is plotted in term of $\mathrm{Cr}(\%) / \mathrm{C}(\%)$ ratio in Fig. 7. Although the data

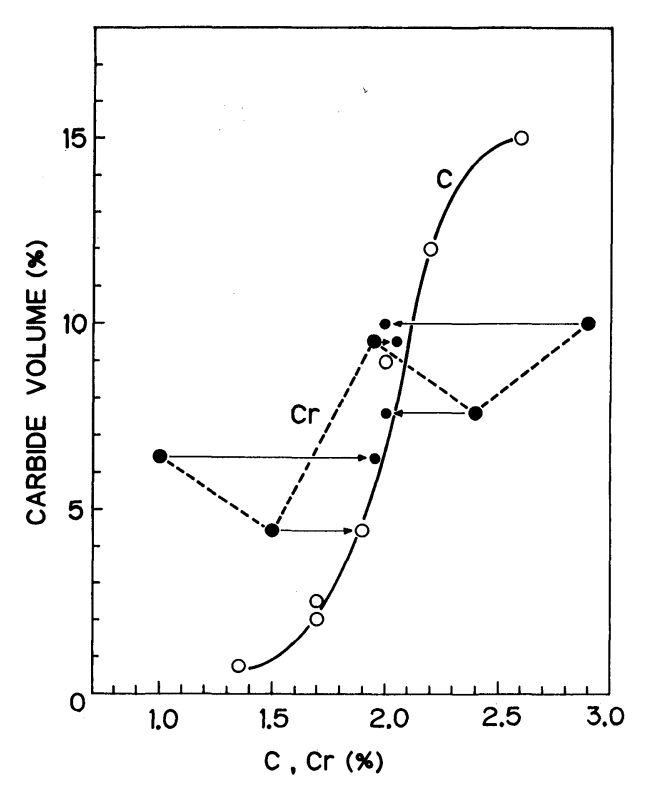

Fig. 5. Dependence of coarse carbide volume fraction on $\mathrm{C}$ and $\mathrm{Cr}$ contents.

are somewhat scattered, a simple proportional correlation is found. Therefore, the amount of $\mathrm{Cr}$ addition must be determined in proportion to the $\mathrm{G}$ content for hardening of these roll materials.

Figure 8 shows the relation between the hardness of coarse carbide and the $\mathrm{Mn}$ and $\mathrm{Ni}$ contents. The 


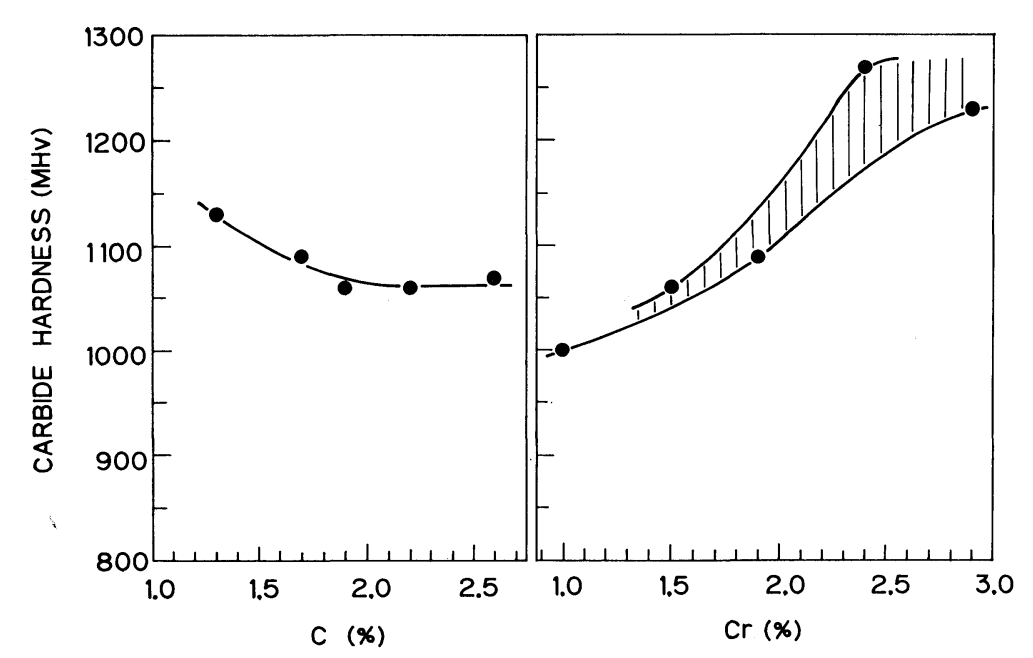

Fig. 6. Variation of the hardness of coarse carbides with $\mathrm{G}$ and $\mathrm{Cr}$ contents.

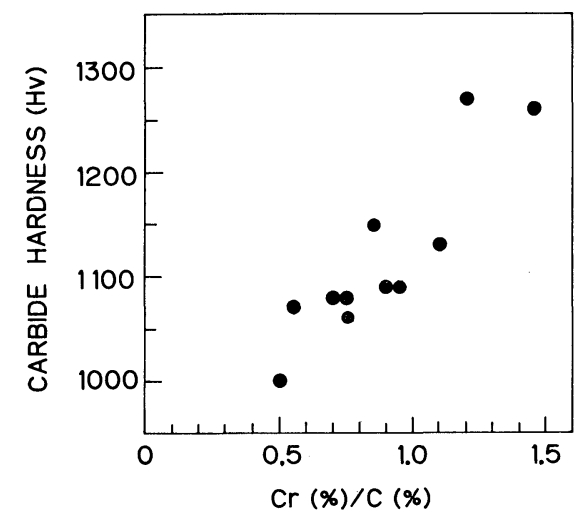

Fig. 7. Variation of the hardness of coarse carbides with $\mathrm{Cr}(\%) / \mathrm{C}(\%)$ ratio.

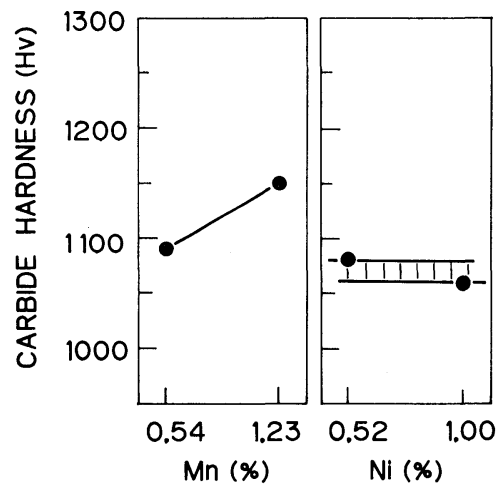

Fig. 8. Variation of the hardness of coarse carbides with $\mathrm{Mn}$ and $\mathrm{Ni}$ contents.

hardness of coarse carbide increases significantly with increasing Mn content and hardly with $\mathrm{Ni}$ content.

3. Effects of Chemical Composition on the Hardness of Matrix

The relation between the hardness of matrix and the $\mathrm{G}$ and $\mathrm{Cr}$ contents is shown in Fig. 9. As is evident from this figure, the hardness of matrix increases with increasing $\mathrm{Cr}$ content and scarcely with $\mathrm{G}$ content. This seems to be a result that the amount of $\mathrm{G}$ in solid solution does not differ significantly in the matrices among these roll materials.

The relation between the hardness of matrix and the $\mathrm{Mn}$ and $\mathrm{Ni}$ contents is shown in Fig. 10. The hardness of matrix increases with increasing $\mathrm{Mn}$ and $\mathrm{Ni}$ contents. It is considered that the effects of these elements on the hardness of matrix are based on the improvement of hardenability and the solid-solutionhardening.

\section{Relation between the Hardness of Adamite Roll} Materials and the Microstructure

As mentioned in Introduction, it can be considered that the adamite roll materials are composite materials of coarse carbide and matrix. Therefore, it is evident that the hardness of adamite roll materials is affected by the amount and hardness of coarse carbide and by the hardness of matrix. The hardness of adamite roll materials $(H s)$ can be expressed as

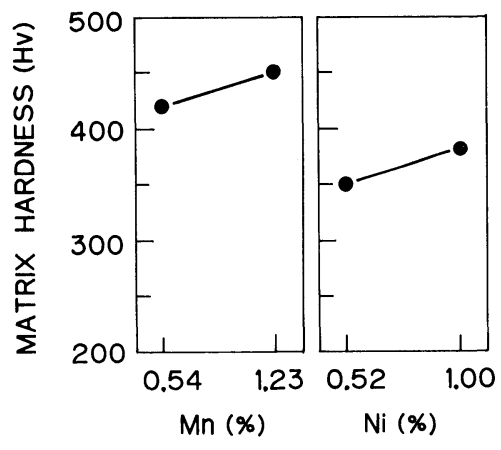

Fig. 10. Dependence of matrix hardness on $\mathrm{Mn}$ and $\mathrm{Ni}$ contents.

$$
H s=(r / 100) \times(a H v+(100-a) \times M H v)+d,
$$

where, $a:$ the coarse carbide volume fraction (\%)

$H v$ : the hardness of coarse carbide

$M H v$ : the matrix hardness

$r, d:$ the constants.

Figure 11 shows the rleation between the measured hardness of the adamite roll materials and the hardness calculated from the above equation with $r=1$ and $d=0$. Although the measured data are scattered, it is proved that the mutual relationship is satisfactorily predicted.

Therefore, the equation for predicting hardness from the microstructure of adamite roll materials can be used to determine the microstructure with a re- 


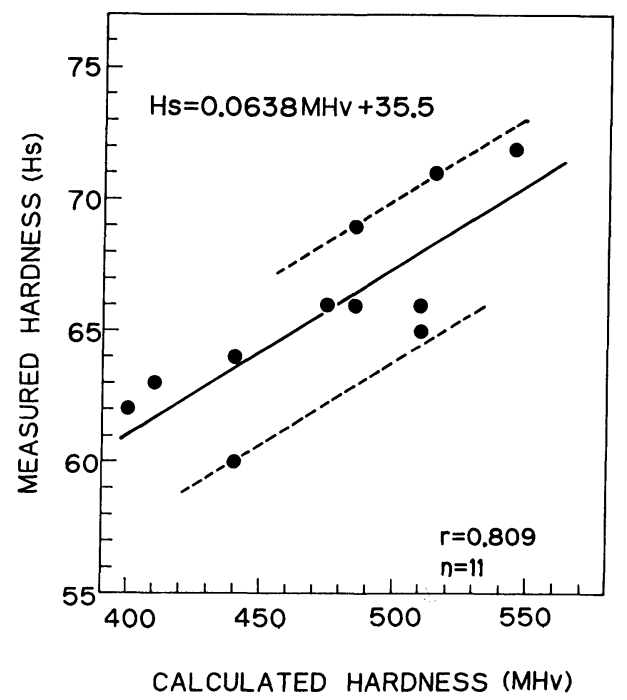

Fig. 11. Comparison of the hardness of adamite measured and calculated.

quired hardness.

\section{Wear Resistance of the High-hardened Adamite Roll Materials}

1. Wear Resistance of the Conventional Roll Materials for Hot Work Roll

High-chromium and high-nickel grain iron roll materials are used commonly for hot work rolls besides the adamite roll materials. Wear resistance of these roll materials at high temperature is markedly affected by the wear conditions, such as temperatures, rolling speeds, loads and slipping rates in testing.

In previous papers, ${ }^{4,5)}$ the dependence of wear resistance of these roll materials on the wear testing conditions was investigated by using the high-temperature wear testing machine. As an example, Fig. 12 shows the relation between wear resistance of these roll materials and rolling speeds in an identical rolling distance. ${ }^{5)}$ The wear resistance of adamite roll materials is affected by rolling speeds more markedly than the other iron roll materials.

Specific wear loss at a high rolling speed decreases when the surface is covered with a black oxide layer having good wear resistance. ${ }^{6,7)}$ The following experiments were carried out by using the worn surface with no black oxide layer.

2. Relation between the Hardness and the Wear Resistance

Figure 13 shows the effects of hardness on the wear resistance in a short and long time wear testing at high temperatures. The short and long time wear resistance improves with increasing hardness.

These experimental results suggest that the wear resistance of these roll materials varies with the hardening mechanisms, for instance, an increase in the amount and the hardness of coarse carbides, and an increase in the hardness of matrix, even if the hardness of these roll materials remains the same.

\section{Effects of the Amount of Coarse Carbide on Wear Resistance}

As discussed in the preceding chapter, the long time

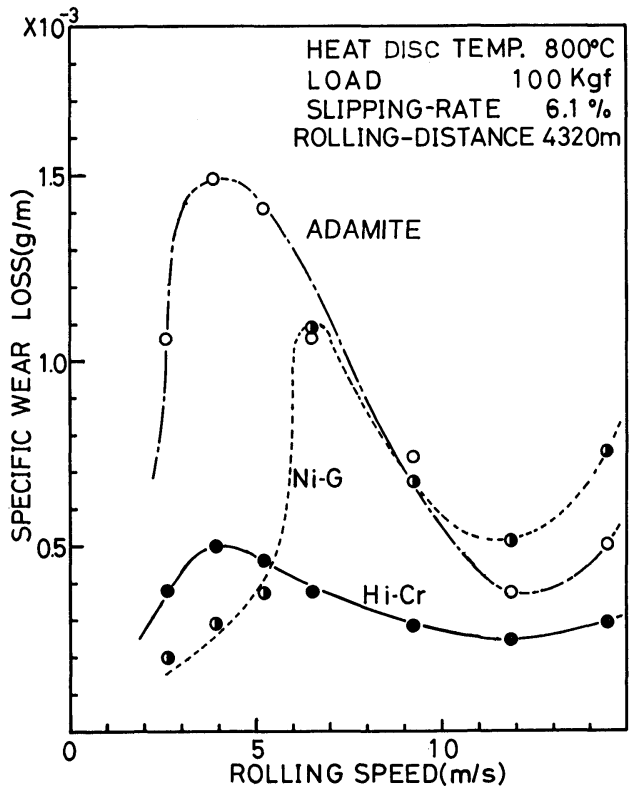

Fig. 12. Effect of rolling speeds on wear resistance of roll materials for hot work rolls.

wear resistance is largely affected by the hardening mechanisms of adamite roll materials. To understand these phenomena, the experimental results in the short and long time wear testing were considered in terms of the coarse carbide volume fraction. The results are shown in Fig. 14; the upper figure for the long time wear resistance and the lower for the short time wear resistance. The wear resistance of these roll materials is highest at a carbide volume fraction of about $8 \%$ and deteriorate remarkably above than $8 \%$.

From Figs. 5 and 14, the $\mathrm{C}$ content of about $2.0 \%$ in the adamite roll materials is concluded to provide a possibility of the best wear resistance.

\section{Effect of the High-hardened Adamite Roll Materials} on the Wear Resistance

It is well known that the hard materials have a good wear resistance. However, from the present experimental results, it is shown that the wear resistance of adamite roll materials is not always improved when these roll materials are hardened by a larger amount of coarse carbides. For the investigation of this cause, the cross-sectional microstructures of these roll materials with a large amount of coarse carbides were observed with optical microscopy.

Figure 15 shows the optical micrographs of worn surface of the roll materials with a larger amount of coarse carbides. Carbides are partly missing because of disintegration. From these findings, it is concluded that the poor wear resistance of adamite roll materials with a larger amount of coarse carbides is caused by the partial disintegration of coarse carbides.

A further question arises why the adamite roll materials with a larger amount of coarse carbides have the tendency toward partial disintegration of the carbides.

Figure 16 shows the relation between the volume fraction and the interspacing of coarse carbide, indi- 


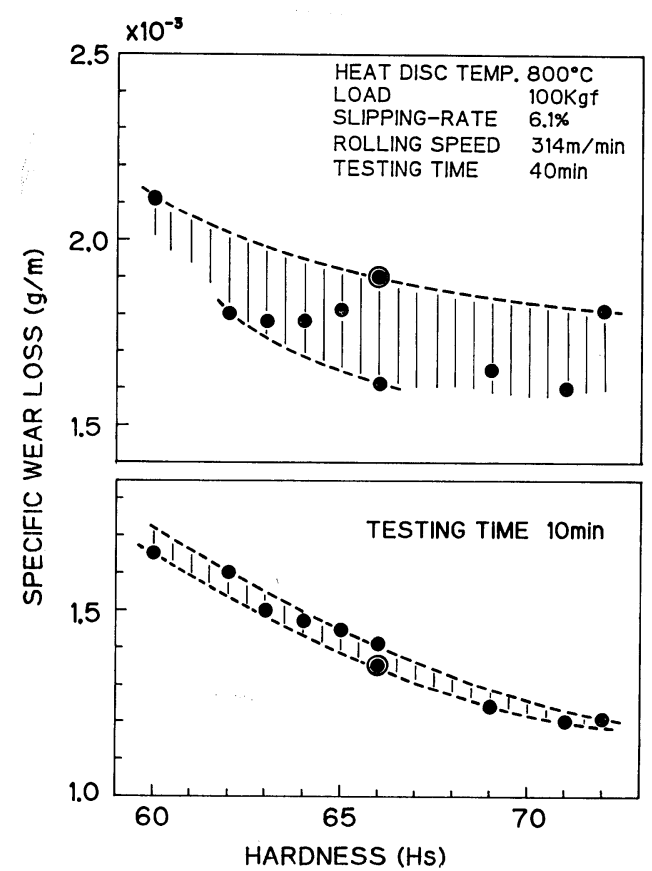

Fig. 13. Effect of hardness on wear resistance in short and long time wear testing at a high temperature.

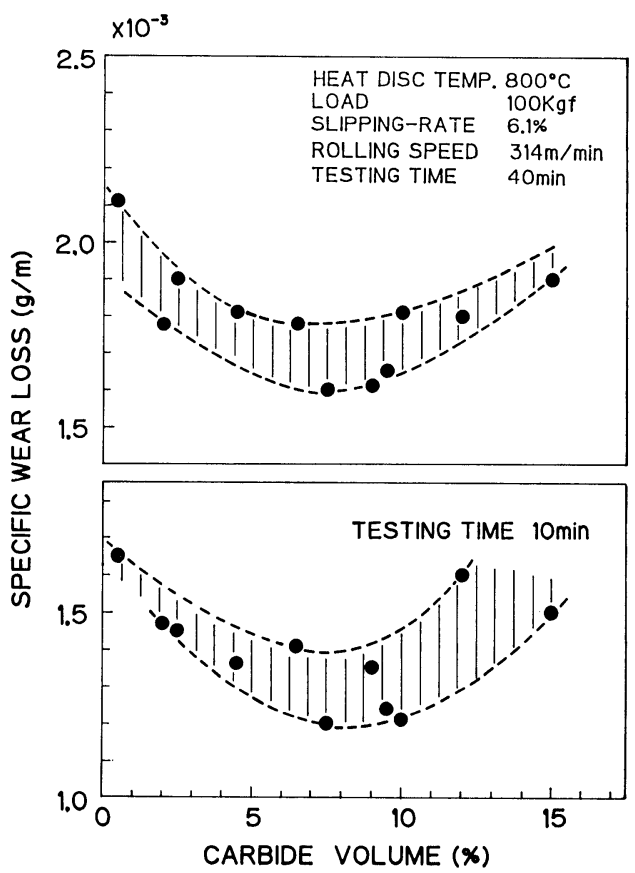

Fig. 14. Effect of carbide volume fraction on wear resistance in short and long time wear testing at a high temperature.

Fig. 15.

Optical micrographs of worn surface of adamite.
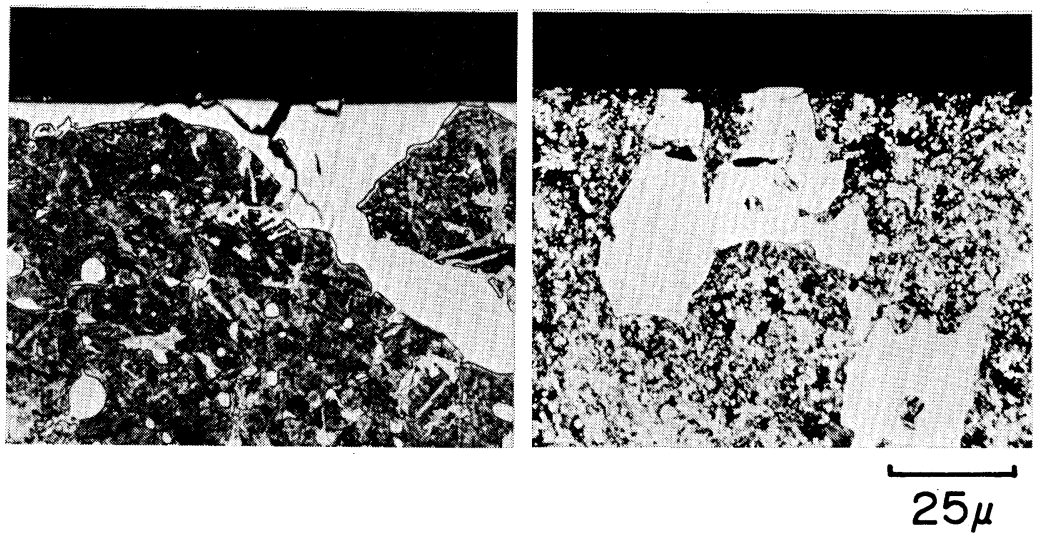

cating the interspacing decreases with increasing volume fraction.

It is considered that the larger amount of coarse carbides, leads to a smaller interparticle spacing, and a larger portion of coarse carbides in contact with the heat disc surface in wear testing.

From the findings described above, the poor wear resistance of adamite roll materials with a large amount of coarse carbides may be caused by the partial disintegration of carbides because of the increased contact areas of brittle coarse carbides.

\section{Conclusions}

The amount of coarse carbides in hardened adamite roll materials is needed to be optimized at about $8 \%$ to ensure good wear resistance. For this purpose, the $\mathrm{C}$ content in adamite roll materials must be limited at about $2 \%$. Furthermore, the adamite roll materials must be hardened by the hardening of coarse carbides with $\mathrm{Cr}$ addition in proportion to $\mathrm{G}$ content. It is also necessary that the matrix is hardened by an addition of $\mathrm{Mn}$ and $\mathrm{Ni}$.

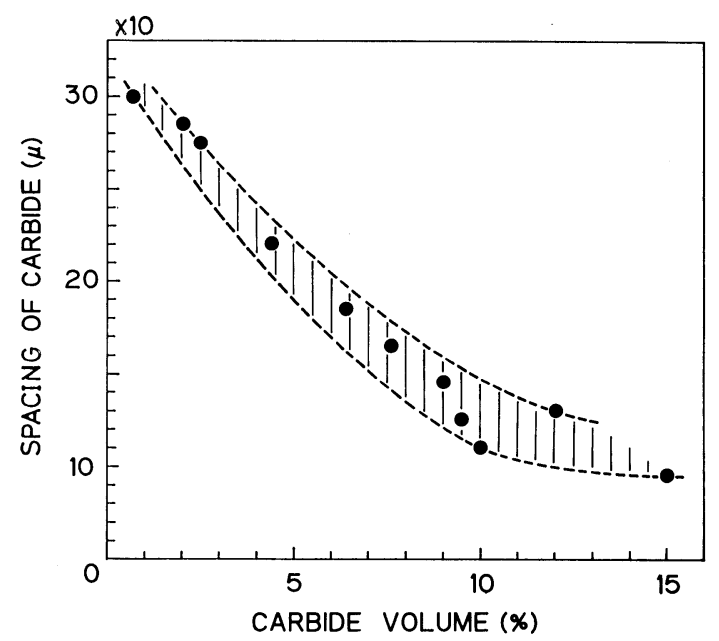

Fig. 16. Relation between volume fraction and interspacing of coarse carbides.

The high-hardened adamite rolls with about $8 \%$ of coarse carbides have a hardness from $\mathrm{Hs} 65$ to 70 and provide a satisfactory result in application to the 
work rolls in hot rolling mill.

\section{REFERENCES}

1) H. Noguchi, Y. Watanabe and T. Enami: Tetsu-to-Hagané, 71 (1985), S1560; Trans. Iron Steel Inst. Jpn., 26 (1986), B229.

2) H. Noguchi, Y. Watanabe and T. Enami: Tetsu-to-Hagané, 72 (1986), S305.

3) K. Ohgi and K. Matsuda: Imono (J. Jpn. Foundrymen's
Soc.), 42 (1970), 999.

4) H. Noguchi, T. Tanaka, K. Kawamoto and S. Umemoto: Tetsu-to-Hagané, 70 (1984), 1452.

5) H. Noguchi and Y. Watanabe: Tetsu-to-Hagané, 70 (1984), S1211.

6) T. Muta, T. Ohgi, I. Masuda and H. Nishina: Tetsu-toHagané, 61 (1975), S281; Trans. Iron Steel Inst. Jpn., 20 (1980), B63.

7) Y. Sekimoto: J. Jpn. Soc. Technol. Plast., 23 (1982), 952. 